\title{
Democracia Deliberativa, Capital Social e Coprodução de Serviços Públicos: Potenciais e Desafios na Construção da Sinergia Estado-Sociedade
}

Deliberative democracy, social capital and co-production of public services: potentials and challenges in

building the state-society synergy

\author{
Victor Barcelos Ferreira ${ }^{1}$ \\ Flávia de Paula Duque Brasil ${ }^{2}$ \\ Bruno Lazzarotti Diniz Costa ${ }^{3}$
}

\begin{abstract}
RESUMO
O presente trabalho pauta-se por investigar a relação entre a institucionalização de instâncias participativas no contexto político local, e os seus efeitos na promoção da co-produção de serviços públicos, com ênfase na gestão escolar. Para tal, buscou-se explorar o conceito de empowered participatory governance (EPG) no estabelecimento de iniciativas deliberativas no âmbito educacional. A literatura de co-produção, no âmbito da economia do setor público, fornece elementos chave para a compreensão da relação entre burocratas escolares e as famílias de alunos. Esses dois campos têm forte interação com os estudos de capital social, que se firma como um insumo essencial para promoção de ações mais integradas e coesas entre Estado e sociedade. A conjugação destas teorias permite apontar potenciais benefícios e pontos de fragilidade para a análise das intervenções. Uma das grandes possibilidades da implementação da EPG é delegar autonomia à governança local e, ao mesmo tempo, construir estruturas accountability quanto ao governo central. Nesta relação, o governo, ao descentralizar a tomada de decisão para o conselho local, estabelece contrapartidas relacionadas ao monitoramento de desempenho, ao passo que capacita os conselheiros para o exercício destas funções. A partir disso, o trabalho pauta-se por discutir os principais potenciais e desafios para implementações baseadas nesses pilares, no provimento da educação pública.
\end{abstract}

Palavras-chave: Democracia deliberativa; capital social; co-produção; gestão educacional.

\begin{abstract}
This paper aims to investigate the relationship between the institutionalization of participatory bodies in the local political context, and its effects on the promotion of co-production of public services, with emphasis on school management. Thus, it sought to explore the concept of empowered participatory governance (EPG) in the establishment of deliberative initiatives in the educational field. Co-production literature, insert in public economies field, provides key elements for understanding the relationship between school bureaucrats and student families. These two fields have a strong interaction with social capital studies, which stand as an essential input for promoting more integrated and cohesive actions between state and society. The combination of these theories makes it possible to point out potential benefits and points of weakness for the analysis of interventions. One of the great possibilities of EPG implementation is to delegate autonomy to local governance while building accountability structures for central government. In this relationship, the government, by decentralizing decision making to the local council, establishes counterparts related to performance monitoring, while empowering the directors to perform these functions. Therefore, the work is guided by discussing the main potentials and challenges for implementations based on these pillars, in the provision of public education.
\end{abstract}

Keywords: Deliberative democracy; share capital; co-production; educational management.

\footnotetext{
${ }^{1}$ Fundação João Pinheiro. Mestrando em Administração Pública, pela Fundação João Pinheiro e Bacharel em Ciências Econômicas, pela Universidade Federal de Viçosa. E-mail: victorbarcelos@msn.com

${ }^{2}$ Fundação João Pinheiro. E-mail: flaviaduquebrasil@gmail.com

${ }^{3}$ Fundação João Pinheiro. E-mail: bruno.diniz@fjp.mg.gov.br.
}

Agradecimentos à CAPES que provém a bolsa de mestrado de um dos autores, sem a qual este trabalho não seria possível. 


\section{Introdução}

A principal característica da democracia, segundo Stuart Mill4, é a capacidade constante de um governo em ser sensível às preferências dos seus cidadãos. Na metade do século passado, apenas 22 países configuravam-se em um modelo democrático, evoluindo para 112, no início dos anos 2000 (WARREN, 2002). Apesar de a escalada democrática propiciar ganhos robustos para a população, em termos de bemestar social, Warren (2002) ressalta a difusão de um movimento de diminuição de expectativas quanto aos regimes democráticos.

Esse fenômeno tem suas origens na ausência de igualdade política, que prediz que todos os indivíduos devem ter as mesmas condições de influenciar nas decisões coletivas. Bobbio (1984) ressalta que as democracias falharam na entrega da educação para a cidadania dos indivíduos, de modo que estes tornaram-se apáticos quanto às questões políticas. De forma premeditada ou não, as instituições políticas influenciam na distribuição dos recursos da sociedade, através das decisões tomadas, e por sua vez, determinam quais atores serão atuantes dentro e fora destas instituições (MARCH e OLSEN, 2010)

Bobbio (1984) apresenta alguns dilemas que surgiram com a deflagração dos regimes democráticos. Dentre eles, o autor pontua que as democracias encontraram na burocracia uma forma de aprimorar o provimento dos serviços públicos à população. No entanto, o estabelecimento da burocracia torna engessada a sensibilidade estatal às demandas da população, comprometendo a própria democracia. No sentido contrário, quando os canais de interlocução não estão comprometidos, pode haver um crescimento vultoso de demandas que pode comprometer a governabilidade.

A resposta a este fenômeno, segundo Pateman (2012), reside na democracia deliberativa. A autora narra a transição que iniciou-se no movimento insurgente na década de 1980, a "onda de participação" que foi amplamente fomentada pelos organismos multilaterais, que deu origem, posteriormente, à emergência das instâncias de deliberação, trazendo a participação cívica para influenciar diretamente no processo de tomada de decisão.

Na mesma linha, Fung e Wright (2001) ressaltam a ineficiência dos dispositivos democráticos em fomentar o envolvimento da sociedade civil, o diálogo em prol de um consenso e a culminância em políticas públicas que assegurem o acesso universal aos recursos públicos. Nesse contexto, o conceito de empowered participatory governance (EPG), cunhado pelos autores, apresenta-se como um potencial mecanismo para a promoção da participação popular, tanto no contexto de expressar suas demandas, quando na redução de custos transacionais no provimento de serviços públicos.

Segundo Fung e Wright (2001), este modelo de governança, ao mesmo tempo em que delega à sociedade a tomada de decisão, a partir de um consenso fundamentado, consegue empoderar diversos atores uma dando-lhes a oportunidade de influenciar nas decisões políticas que afetarão diretamente suas vidas.

O presente artigo pautar-se-á por analisar as potencialidades e desafios da implementação de modelos de EPG no sentido de solucionar dilemas de ação coletiva e agente-principal recorrentes no provimento de serviços públicos educacionais. Para tal, duas outras correntes teóricas que dialogam com a temática fazemse oportunas. A primeira delas discorre sobre a coprodução de serviços públicos, baseada no relacionamento entre os beneficiários e os provedores diretos, que podem funcionar com dispositivos práticos para aprimorar o mecanismo de EPG. Ao mesmo tempo, as teorias que se debruçam sobre o capital social fazem-se necessárias para discussão. Tendo em vista a natureza dos processos de tomada de decisão, e posteriormente, de implementação, em um contexto de aplicação de EPG, os laços de confiança da população agem para a promoção da cooperação (Putnam, 2002)

\footnotetext{
${ }^{4}$ Stuart Mill (1948), apud Putnam (2002, p. 77)
} 
Com o intuito de debruçar-se sobre o tema exposto, o seguinte construirá o referencial teórico a partir da discussão das temáticas de empowered presente trabalho conta com mais cinco seções além desta introdução. A seção participatory governance, co-produção e capital social. Posteriormente, será construída uma metodologia de análise, a partir do que foi discutido na segunda seção. Em seguida, constará uma avaliação de casos empíricos, e discutidos a partir da teoria sedimentada. A quinta seção discorrerá sobre as potencialidades e percalços do modelo defendido, e por fim, serão feitas algumas considerações finais sobre o tema.

\section{Referencial Teórico}

\subsection{Descentralização e deliberação}

O termo empowered participatory governance, é cunhado por Fung e Wright (2001) a partir da análise de casos sobre iniciativas que promoveram reformas no aparato estatal incorporando novas arenas de deliberação. $O$ intuito dessas novas instituições era açambarcar as preferências da população, de forma mais direta, em decisões que até então seriam pré-concebidas como competentes ao alto-escalão da burocracia em conjunto com os governantes. Os casos analisados no livro Deepening Democracy, por Fung e Wright (2001) e colaboradores, tratam de arenas de deliberação em políticas nas áreas de educação, segurança pública, meio-ambiente, planejamento e fiscal.

Este bojo de reformas suscita duas críticas centrais, formatadas por Abers (2003), e que nortearão as discussões doravante: porque o governo se interessaria em transferir o poder da tomada de decisão para estas instâncias deliberativas compostas de pessoas comuns, e porque estas mesmas pessoas, sem engajamento político prévio, se proporiam a este trabalho, dedicando seu tempo e recursos próprios para o exercício desta função?

Fung e Wright (2001), em algumas reflexões, ponderam que talvez a Era do "Estado democrático afirmativo", colocando este como um ente que atua de forma ativa e criativa para solucionar as demandas sociais, tenha se esgotado. Ao mesmo tempo, diante do puzzle entre esse esgotamento e os constrangimentos à participação popular, deposita a esperança no design das instituições políticas em vigor.

Aprofundando nesta linha dos dilemas da participação, algumas outras questões emergentes no esgotamento da democracia participativa, no fim da década de 80. Como demonstrado por Warren (2002), não houve um rompimento com os valores democráticos, como se aparentava, no entanto houve um aumento de expectativas quanto aos governantes. Os cidadãos passaram a exigir maior responsividade, eficiência e accountability, além de aumentar a aversão à corrupção. Outro dilema flagrante, resgatado por Abers e Keck (2009), consiste no fato de que, a deliberação e a participação apenas enraizarão na democracia se houver capacidade estatal para executar as decisões deliberadas, e, mais profundamente, se as normas vinculantes deliberadas verterem em mudança de comportamento público.

A partir destes dilemas, o presente artigo compreende a vertente EPG como um caminho para solucionar estes problemas, em âmbito local, e os consequentes entraves que geram ao provimento de bens coletivos. Para tal, Fung e Wright (2001) pontuam três princípios que devem ser constados para a efetividade das reformas com essa diretriz. O primeiro princípio salienta que as estruturas de governo criadas para a deliberação devem ser orientadas para a solução de problemas práticos e exequíveis. Isto fará com que atores que, historicamente estão acostumados a disputar por poder e recursos, sejam forçados a cooperarem e estabelecer um consenso - o que deve ser prioritário no estabelecimento do arranjo institucional.

O segundo princípio está ligado à participação bottom-up, de atores diretamente afetados pelo problema, 
dos quais será necessária a articulação de conhecimentos e interesses para formular soluções. Os autores ressaltam que determinados problemas que envolvem uma multiplicidade de interesses, por vezes requerem uma interação de diversos pontos de vista, com bagagens, repertórios e conhecimentos distintos e mentalidade mais aberta, em comparação com os burocratas, que se encontram distante da realidade. A atribuição dos experts, neste caso, seria mediar e facilitar o processo de tomada de decisão entre os diversos atores envolvidos. O ganho dessa estratégia é aumentar a accountability dos governos, ao passo que a cadeia entre a população e os executores da política torna-se menor.

Por fim, o terceiro princípio está relacionado à geração de uma solução, a partir do processo deliberativo. Na prática, o que se preza é o debate entre diferentes pontos de vista e a convergência para um consenso. Fung e Wright (2001) ressaltam que esse processo não está livre de turbulências, uma vez que as pessoas não agirão de forma altruísta, e, portanto, espera-se uma solução aceitável, diante de todos os constrangimentos - não necessariamente uma solução ótima. Os autores ressaltam que o estímulo à participação está ligado a uma instância maior do que a pressão na agenda prévia do governo, mas à expectativa de que de fato a solução deliberada seja de fato incorporada na agenda, a partir de então, e posteriormente, implementada.

Estes princípios expostos convergem no sentido de um desenvolvimento deliberativo, que, segundo Evans (2010) constituem um dos pilares de políticas econômicas e políticas públicas eficazes no século XXI. A literatura denomina como sinergia o estreitamento do relacionamento do Estado com a sociedade, que materaliza-se na criação de normas de cooperação e relações sociais entre atores estatais e civis (EVANS, 1996).

O estudo de Hellers (2001) demonstra algumas implicações de um processo de construção democrática, em locais onde o Estado e a sociedade culminaram para um estado sinérgico, tais como: maior incentivo ao associativismo, criação de espaços deliberativos alinhados ao planejamento governamental e construção de consensos entre a tecnocracia e a população local. Portanto, entende-se que as reformas orientadas para a EPG surgem em um determinado contexto específico, havendo sinergia na relação Estadosociedade.

Conforme ressalta Evans (1996), a literatura trata o tema co-produção e sinergia de formas similares. O próximo tópico objetiva explorar os dois conceitos, bem como suas interseções e distinções, e relacionar com o conceito de empowered participation governance.

\subsection{Co-produção de serviços públicos e sinergia Estado-sociedade}

Segundo Ostrom (1996), a co-produção ocorre quando o provimento de um bem ou serviço é oriundo de um processo no qual os atores envolvidos no processo, e depositaram recursos para tal, não pertencem a uma mesma organização. A autora ressalta que na esfera pública, os casos mais recorrentes na qual se constata a coprodução são os serviços ofertados de forma regular, em áreas com educação, saúde e infraestrutura.

Além disso, afirma o processo produtivo de todos os bens e serviços, envolvem participação do produtor e, de forma variável, do cliente. Contudo, para a ocorrência da coprodução, é necessário que o beneficiário não seja passivo no processo, participando ativamente. Outros autores concebem que a coprodução é uma relação que se estende por toda a cadeia produtiva, perpassando pelo planejamento, desenho, discussão, gestão, implementação, monitoramento e avaliação (BOVAIRD, 2007).

A observância desse fenômeno na prática ocorre através da construção de um relacionamento entre os indivíduos da organização provedora - no caso governamental, a burocracia no nível de rua - e os seus "clientes", isto é, os cidadãos que serão beneficiados pelo serviço ou bem público. Ostrom (1996) ainda 
estabelece um paralelo com as teorias econômicas da produção, uma vez que um determinado bem pode ser produzido a partir de diferentes combinações dos seus fatores de produção - terra, capital e trabalho. Da mesma maneira, um bem-público pode ser obtido a partir de combinações diferentes dos níveis de insumos ou recursos dos atores envolvidos na sua produção: burocratas e cidadãos.

A partir disso, a autora teoriza sua concepção sobre as distinções entre sinergia e coprodução. Segundo Ostrom (1996), só é possível obter sinergia entre Estado e sociedade, quando há coprodução, isto é, ambos os entes estão doando níveis significativos de recursos para o provimento de serviços públicos. Embora Evans (1996) entenda os dois fenômenos como correlatos, o autor ressalta que a literatura tem tratado a coprodução para os processos que envolvem a produção coletiva entre múltiplos atores, enquanto a sinergia é concernente às consequências sociais e institucionais da aproximação entre Estado e cidadãos.

De tal maneira, o autor entende que a sinergia é obtida pela interação de dois mecanismos institucionais, que ele denomina de complementariedade e inserção. O primeiro conceito está relacionado à interação institucionalizada entre entes governamentais e sociedade civil, na qual ambos participam em termos de utilização de recursos, contudo, há uma divisão de trabalho pré-estabelecida e bem delineada. De forma distinta, a inserção ocorre quando é estabelecida uma rede, marcada pela intensificação dos laços de interação social entre estes atores, produzindo arranjos cooperativos. Na presente seção, a discussão será direcionada as interações institucionalizadas, haja vista que o aspecto da inserção estabelece um paralelo com o estoque e a criação de capital social, o que será discutido no próximo tópico.

O trabalho de Parks et al (1981) sugere alguns arranjos institucionais para assegurar que, no contexto de coprodução, tanto os produtores regulares quando os consumidores produtores estejam colaborando, isto é, dispendendo recursos. O primeiro modelo se assemelha ao funcionamento do mercado, atrelando a precificação aos custos de oportunidade dos atores. Contudo, em atividades coletivas por natureza, onde os insumos dos produtores e consumidores são interdependentes, esse modelo pode falhar, considerando o risco de um ator relegar a sua participação, dada a preferência que outros the forneçam o serviço.

Sendo assim, Parks et al (1981) sugerem um modelo hierárquico no qual haja um ator superior que monitore a dedicação dos envolvidos na coprodução, partindo do pressuposto que a organização produz resultados melhores para todos, e que o enforcement exercido por este monitor assegurará isto. Este modelo converge com o conceito de policentrismo, cunhado por Ostrom, Tiebout e Warren (1961), que se define como a existência de vários centros de tomada de decisão, independentes entre si.

Os autores cunham o termo policentrismo ao analisar modelos de provimento de bens públicos entre governos locais em regiões metropolitanas. Segundo Ostrom, Tiebout e Warren (1961), o alto nível de conflito entre os locais pode centralizar a tomada de decisão e produzir distorções, devido ao distanciamento da comunidade política. O sistema político policêntrico, por outro lado, confere mais autonomia aos governos locais. Para tal, o desenho desse sistema deve obedecer aos seguintes critérios: controle do governo central, eficiência no provimento dos bens públicos, representação política e autodeterminação.

Retomando a discussão que permeia o objetivo central deste trabalho, os últimos dois critérios ressaltados acima estão intimamente relacionados ao conceito de empowered participatory governance, cunhado por Fung e Wright (2001). Primeiramente, no concernente à representação política, Ostrom, Tiebout e Warren (1961), ressaltam a necessidade de dar voz à população diretamente envolvida no processo deliberativo, através da representação na comunidade política, isto é, aqueles que decidem o que será implementado, e de que maneira. Caso contrário, ressaltam, seus interesses terminarão por ser desprezados.

Além deste preceito, outro critério do sistema policêntrico que traz similaridades com o modelo EPG, é o que estabelece a autodeterminação. Ostrom, Tiebout e Warren (1961) teorizam que os demais critérios requeridos para a existência do sistema em questão podem ser formulados a partir de fundamentos gerais, no entanto, o que garantirá a sua aplicação será as instituições políticas e os seus poderes para executar o 
que decidem. Sendo assim, é fundamental que estas instituições sejam subordinadas aos interesses dos cidadãos, ou seja, que estes possuam autodeterminação das decisões políticas comunitárias.

Ambos os conceitos dialogam com Fung e Wright (2001) na medida em que estabelecem a governança bottom-up, com envolvimento e representatividade plena das partes interessadas, e com empoderamento para execução das deliberações. Ostrom (1996) ressalta que o sistema policentrico tem potenciais características para fomentar a coprodução, na medida em que as unidades locais de tomada de decisão são menores e estimulam o estreitamento de laços entre a população e os burocratas.

A despeito de todo esse arcabouço, em ambas as correntes teóricas, há uma fragilidade eminente dos sistemas propostos que se debruçam sobre os riscos dos atores manifestarem comportamentos não cooperativos. Desta forma, os autores ressaltam a importância do estoque de capital social para estabelecer um ambiente que propicie a sinergia entre estado e sociedade (EVANS, 1996) e consequentemente a coprodução (OSTROM, 1996). De forma análoga, Heller e Isaac (2003), ao analisar reformas de EPG, ressaltam que comunidades com alto estoque de capital social, manifestam-se com maior engajamento cívico, o que, consequentemente ocasionará uma maior efetividade nas instituições democráticas locais. Devido a esse consenso, entre ambas correntes teóricas, o próximo tópico objetiva discutir o relacionamento entre a coprodução de serviços públicos e instituições de empowered participatory governance.

\subsection{Capital social: insumo e resultado para a sinergia Estado-sociedade}

A despeito da diversidade de problemas que afloram nas sociedades, muito em detrimento das falhas no processo de cooperação entre indivíduos, a temática do capital social tem emergido no campo das ciências sociais como um diagnóstico possível (PUTNAM, 1993). Prates, Carvalhaes e Silva (2007) discutem os diversos conceitos de capital social, e suas respectivas tradições teóricas, dentre os quais, podem ser agregados em dois conjuntos conceituais: o primeiro que entende o capital social em uma perspectiva individual-utilitária, e o segundo o relaciona como um agregado de práticas institucionalizadas de cultura cívica.

Este segundo escopo tangencia diretamente a temática do presente artigo, e desta forma, dar-se-á ênfase e será explorado adiante. $O$ autor que protagoniza esta vertente teórica é Robert Putnam, e parte de uma conceituação de capital social como um conjunto de aspectos relacionados à organização social, tais como normas, redes e laços de confiança que facilitam a coordenação e a cooperação. Como ressaltado por Williamson (1989), estes mecanismos atuam no sentido de diminuir custos de transação entre contratos sociais, o que Putnam (1993) ressalta como uma ferramenta de superar dilemas de ação coletiva e neutralizar dilemas do prisioneiro.

No concernente à temática do presente artigo, Bobbio (2003) ressalta que o capital social relaciona-se com a democracia deliberativa, ora como insumo - ou pré-condição -, ora com um resultado. Ostrom (1996) estabelece como um dos pressupostos para o estabelecimento da coprodução a existência prévia de confiança mútua, entre ambas as partes, de uma para com a outra, para assegurar seus níveis de input. Sendo assim, comunidades com maior nível de capital social tenderiam a ser mais propensas à realização da coprodução.

Por outro lado, pensando no capital social como resultado, a definição de Hirschman (1984) auxilia a compreensão, considerando o capital social como um recurso moral, uma vez que sua oferta aumenta com o uso. Desta forma, quanto mais as pessoas confiam umas nas outras, terão maior engajamento em atividades que lhe proporcionarão um aumento deste estoque de confiança, como resultado. No entanto, Putnam (1993) ressalta que a geração de capital social é um subproduto de outras atividades sociais. Fearon (1997) explica que as arenas deliberativas geram como produto principal um aprimoramento da tomada de 
decisão coletiva, da resolução de conflitos e estabelecimento de consensos, ao passo que o estreitamento das relações de confiança é um efeito secundário.

Esse comportamento dual origina o que Putnam (1993) denomina círculo virtuoso das comunidades cívicas - àquelas com sólidos instrumentos de participação cívica - promovendo alto nível de cooperação. No entanto, o autor ressalta que a mesma lógica poderia funcionar para um círculo vicioso, no qual a retroalimentação do sistema resulte em estoques cada vez menores de capital social, onde o nível inicial já é baixo. Esta lógica consistiria num problema para iniciativas voltadas a inserção da população através da implementação de instâncias de EPG. No entanto, o caso do orçamento participativo, ressaltado por Avritzer (2003), mostra que, o programa foi engendrado e consolidado em locais com alto nível de associativismo, no entanto, propagou-se para cidades onde não era noticiado esse comportamento prévio da população.

Por fim, o comportamento cooperativo de uma população, e a sua percepção por estes, faz com que os indivíduos se reconheçam dentro de um sistema de solidariedade. Segundo Pizzorno (1975), este sistema opera na sociedade em conjunto com os sistemas de interesse, de modo que a participação política é concebida como a articulação de ambos. $O$ autor estabelece que os atores só participam entre iguais, isto é, em áreas nas quais se reconheçam e tenham afinidade e identidade. Este argumento é fundante para justificar que, embora o estoque de capital social proporcione uma maior cooperação e atuação dos atores, é necessário canalizar sua atenção para áreas de interesse substantivo, assegurando maior eficácia nos resultados da deliberação. Portanto, o estabelecimento de arenas para resolução de problemas concretos e viáveis constitui um grande estímulo para a participação dos atores e, por consequência, produtos mais robustos gerados a partir dos inputs de partes públicas e particulares.

\subsection{Aspectos institucionais da produção de serviços educacionais}

A provisão de serviços educacionais está imbuída em uma complexidade institucional, decorrente da dicotomia entre o retorno público e o retorno privado gerado por este (DAVIS; OSTROM, 1991). A despeito disso, Davis e Ostrom (1991) analisam as cadeias de escolhas que influenciam nos resultados educacionais, caracterizada por uma multiplicidade de atores, de diferentes esferas e hierarquias, que têm poder de influência.

Neste âmbito, as autoras diagnosticam a presença de dois dilemas agente-principal que originam esta dicotomia entre público e privado. O primeiro deles, parte do pressuposto que a educação é um investimento de longo prazo, construído a partir de uma série de decisões cumulativas. O principal beneficiário desse investimento será a criança, quando for adulta. No entanto, por incapacidade de tomar uma decisão racional no momento presente, os seus responsáveis exercerão papel de agente na tomada de decisão, por algo que, embora lhes afete diretamente, exercerá maior efeito nos seus filhos.

Além disso, no aspecto coletivo, Davis e Ostrom (1991) ressaltam que a educação tende a gerar externalidades positivas para a comunidade, que, como principal, demandam educação pública de qualidade, uma vez que pagam impostos para tal. Apesar disso, os custos de ação coletiva são uma barreira para que a comunidade se organize para exigir estes benefícios indiretos (i.e. geração de renda, aumento da participação e engajamento cívico). Sendo assim, a comunidade elege representantes para agirem em consonância com seus objetivos, sem que, no entanto, sejam os principais beneficiários das políticas que executarão, constituindo outro dilema agente-principal.

Esta constatação das autoras baseia-se em uma análise em que delineiam o encadeamento de decisões que envolvem o processo educacional, sendo os principais atores: os eleitores, os governantes (a nível estadual e local), os diretores da escola, os professores, os pais e os próprios alunos. As decisões específicas de cada um estão expostas na Tabela 1. 
Tabela 1 - Encadeamento de decisões envolvidas no processo educacional

\begin{tabular}{|c|c|}
\hline Ator social & Decisões \\
\hline Eleitores & $\begin{array}{l}\text { Elegem governadores e prefeitos } \\
\text { Influenciam nas instituições políticas, locais e estaduais }\end{array}$ \\
\hline Governadores & $\begin{array}{l}\text { Orçamento estadual para educação } \\
\text { Currículo, modelos de governança e gestão e avaliação }\end{array}$ \\
\hline Prefeitos & $\begin{array}{l}\text { Orçamento municipal para educação } \\
\text { Métodos para monitoramento e avaliação do desempenho } \\
\text { Modelo de escola e suporte dado para cada unidade }\end{array}$ \\
\hline Diretor escolar & $\begin{array}{l}\text { Política pedagógica interna da escola } \\
\text { Professores } \\
\text { Métodos para monitoramento e avaliação do desempenho dos professores } \\
\text { Critérios de tratamento do alunado }\end{array}$ \\
\hline Professores & $\begin{array}{l}\text { Serem professores do ensino público ou privado } \\
\text { Métodos para estimular alunos e pais } \\
\text { Metodologias de ensino }\end{array}$ \\
\hline Pais & $\begin{array}{l}\text { Matricular os filhos no ensino público ou privado } \\
\text { Nível de dedicação à educação dos filhos } \\
\text { Nível de dedicação à participação na escola } \\
\text { Qual escola pública matricular }\end{array}$ \\
\hline Alunos & $\begin{array}{l}\text { Aspirações internas } \\
\text { Nível de dedicação ao estudo } \\
\text { Relacionamento com professores e demais alunos }\end{array}$ \\
\hline
\end{tabular}

Fonte: Adaptado de Davis e Ostrom (1991)

Uma análise complementar a essa exposta, no contexto da produção, foi realizada por Pestoff (2006). Segundo o autor, a coprodução em educação pode ser realizada pelos pais em quatro instâncias: políticas, econômicas, pedagógicas e sociais. A esfera política é referente à participação em instâncias consultivas ou deliberativas. A econômica diz respeito ao emprego de recursos para suportar o funcionamento da escola, seja em tempo ou recursos materiais e financeiros. A coprodução social concebe a constituição de 
uma rede de relacionamentos em prol da educação dos filhos e, por fim, a instância pedagógica está relacionada ao acompanhamento das atividades rotineiras dos filhos, referentes à escola.

A partir dessas contribuições, constitui-se um sólido arcabouço que permitirá a análise de casos concretos, ressaltados pela literatura, na qual, abordam mais especificamente a questão da coprodução ou a questão de reformas inclinadas para empowered participatory governance. Desta forma, a próxima seção fará uma sistematização dos principais conceitos abordados até então, de forma a serem abarcados na análise.

\section{Metodologia}

Diante dos conceitos trazidos no referencial teórico, construiu-se uma matriz de referência para analisar os casos levantados pela literatura, na fronteira com o tema do presente trabalho. A Tabela 2 expressa a matriz com os atores que serão analisados, bem como quais as condições são esperadas para que seja captada uma sinergia entre Estado e sociedade, com instâncias de participação e deliberação institucionalizadas, favorecendo a emergência da coprodução.

Tabela 2 - Matriz de referência para análise

\begin{tabular}{|c|c|c|}
\hline Ator social & Comportamento desejado & Atitudes esperadas \\
\hline $\begin{array}{l}\text { Governos (locais e } \\
\text { estaduais) }\end{array}$ & Descentralização de poder & Favorecem a criação de instâncias deliberativas \\
\hline Burocratas & $\begin{array}{l}\text { Abertura para participação } \\
\text { parental }\end{array}$ & $\begin{array}{l}\text { Mudanças de práticas a partir da interação e sinergia } \\
\text { com as demandas parentais }\end{array}$ \\
\hline Pais & $\begin{array}{l}\text { Envolvimento com as } \\
\text { atividades escolares }\end{array}$ & Participação econômica, social, política e pedagógica \\
\hline Comunidade & $\begin{array}{l}\text { Tradição prévia ao } \\
\text { engajamento cívico }\end{array}$ & Participação política, associativismo e cooperação \\
\hline
\end{tabular}

Fonte: Elaboração propria.

A construção parte do encadeamento de escolhas, e seus respectivos atores, envolvidos no processo educacional, concebido por Davis e Ostrom (1991), exposto na Tabela 1. A partir disso, levará em consideração se os pressupostos estabelecidos por Fung e Wright (2003) para a emergência da EPG podem ser captados a partir de ações dos governos, estaduais e locais. 
Quanto à burocracia, compreende-se os burocratas no nível de rua, neste caso, os professores, que proveem diretamente o serviço, tanto os burocratas de médio escalão, que intermediam as decisões entre o setor político e a execução propriamente dita da política em questão (Lipsky, 1980; Lotta et al, 2014). Como ressalta Taylor e Kelly (2006), novas estruturas de governança e relações intensificadas com a comunidade afetam a discricionariedade destes profissionais, gerando novas estruturas e processos. Desta forma, a análise objetiva encontrar relatos de mudanças de comportamento e atitude destes profissionais, alinhadas com as demandas e anseios da comunidade.

Das atitudes relatadas pelos pais, espera-se captar sinais de participação, nas quatro formas diagnosticadas por Pestoff (2006), bem como implicações e relações causais entre estas. Embora na cadeia produção da educação, elaborada por Davis e Ostrom (1991), incorpore os estudantes como relevantes tomadores de decisão, optou-se por não incorporá-los, utilizando o pressuposto ressaltado no mesmo trabalho, de que os pais são encarregados, em muitos casos, de tomar decisões pelos filhos. Por fim, com a análise da comunidade, espera-se captar o efeito do capital social, que tenderia a fortalecer o laço entre os demais atores sociais, assegurando confiança e credibilidade para que mantenham seus níveis de inputs (OSTROM, 1996).

Serão analisados dois casos evidenciados na literatura. O primeiro deles está contido no artigo Fung (2003), no qual o autor analisa a implementação dos conselhos escolares locais (local school council - LSC) na rede pública de Chicago. O segundo caso será pautado na análise de Bifulco e Ladd (2005), sobre a coprodução nas Charter Schools - uma modalidade de escola independente, vigente nos Estados Unidos. A intenção da escolha dos dois artigos é comparar literaturas que abordam os dois conceitos que o presente trabalho relaciona: empowered participatory governance e co-produção, tratados nos dois artigos a serem analisados, respectivamente. Desta forma, será possível analisar se as escolhas adotadas no alto escalão do governo, buscando a construção de uma sinergia com a população, tendem a fomentar a coprodução, bem como o movimento inverso, gerando um movimento bottom-up de influência na agenda política.

\section{Discussão Analítica}

\subsection{As reformas no sistema educacional de Chicago}

O artigo de Fung (2003) analisa as reformas as reformas educacionais no sistema público de Chicago que objetivou descentralizar a tomada de decisão, aumentando a participação comunitária neste processo. A partir de 1988 as escolas da rede pública do município começaram a ser governadas por conselhos escolares (local school council - LSC), totalizando 540 unidades.

Os conselhos eram eleitos democraticamente, com renovação a cada dois anos, e compostos por: seis pais de alunos, dois representantes da comunidade, dois professores e o diretor da escola, além de um aluno do ensino médio convidado, todavia sem poder de voto. Dentre as suas responsabilidades e poderes estavam: a eleição e demissão do diretor, gestão dos fundos, elaboração e execução do projeto político pedagógico, reformas na infraestrutura da escola e procedimentos administrativos. A partir da matriz de análise elaborada, é notório que a composição do conselho concebe a participação de parte dos atores considerados, sendo estes: a burocracia, os pais de alunos e a comunidade, no entanto, não distribuídos de maneira equânime.

Embora não houvesse representantes do governo no conselho, Fung (2003) ressalta que este arranjo institucional adotado possui características tanto de centralização quanto de descentralização. Competia ao governo central dar suporte aos conselhos locais, através de capacitações aos membros em áreas como gestão orçamentária, elaboração do currículo pedagógico e planejamento estratégico, além de dar 
orientações para a seleção do diretor. Por outro lado, foram implantados mecanismos de garantir a responsividade dos conselhos, através do monitoramento do plano anual que cada unidade elaborava, a partir de suas deliberações. Segundo o autor, este funcionamento assegurava empoderamento dos conselheiros, ao passo que lhes era garantido a autonomia para deliberação e, posteriormente, execução das ações em consenso, ao mesmo tempo em que garantia accountability, pelos mecanismos de prestação de contas ao governo central.

De acordo com que se espera para a presente a análise, as ações governamentais estão coerentes com a proposta de favorecer a autogovernança, com criação de instâncias deliberativas. Além disso, o estabelecimento de uma distância da tomada de decisões, assumindo uma postura de monitoramento das ações, inclina-se para uma imparcialidade diante das deliberações dos conselhos. As intervenções só ocorriam em situações na qual o conselho deixava de prestar contas ou diante da ineficácia da escola, refletida pelo desempenho educacional. No entanto, como ressalta o autor, as ações tinham caráter de orientação, isto é, objetivando reconstruir a autonomia da gestão local.

Este modelo de gestão produz impactos significativos na execução das atividades educacionais, logo, beneficiando os professores. Segundo Fung (2003), a possibilidade de interferir de maneira mais efetiva e direta no estabelecimento dos meios e fins a serem adotados, sem imposições hierárquicas, garantia maior autonomia aos professores. Um exemplo citado de resultado gerado que converge nesse sentido é a reestruturação da carga horária dos professores, em diversas escolas, para que tivessem maior tempo de dedicação ao planejamento das aulas e atividades externas à classe.

Quanto aos diretores, ao mesmo tempo em que participavam do conselho, eram monitorados pelo órgão, uma vez que eram incumbidos de executar o plano de ação deliberado. $O$ autor ressalta que, ainda assim, este arranjo propicia maior autonomia ao gestor, que conduzia o processo de elaboração do plano, haja vista que possuíam maior conhecimento dos trâmites administrativos. No entanto, era necessário que todas as demais representações - pais de alunos e professores - fossem levadas em consideração, tendo em vista que era permitido ao conselho a demissão do diretor, além das potenciais sanções impostas a estes pelo governo central, no caso de violação do cumprimento das deliberações.

A ação parental era amplamente contemplada com representação majoritária no conselho, com seis das doze cadeiras disponíveis. Fung (2003) ressalta que ao participar dos conselhos, os pais tinham expectativas de que suas demandas seriam incorporadas na delineação de soluções para os problemas locais que afetam o cotidiano da escola. $O$ autor ainda pontua que mesmo que as opiniões não fossem incorporadas na elaboração do plano de ação, o arranjo assegurava que os pais pudessem vocalizar seus pontos de vista.

Na discussão apresentada no trabalho, é possível notar que os pais tinham influência nas políticas e na execução pedagógica dos trabalhos da escola. Contudo, não é possível identificar exemplos de coprodução para além das atividades do conselho, através do estreitamento de relações entre os pais e os burocratas. Outro ponto que constitui um desafio para o avanço deste modelo é a correlação negativa entre o percentual de estudantes de baixa renda com a participação parental nos conselhos. De toda maneira, a obrigatoriedade da participação parental no conselho pode interferir para amenizar o primeiro dilema-agente principal da educação, ressaltado por Davis e Ostrom (1991), uma vez que os pais serão convidados a participarem de forma mais ativa sobre as decisões que exercerão impacto direto sobre os seus filhos.

Por fim, o conselho estabelece que dois assentos devem ser ocupados por representantes comunitários que tenham interesse em colaborar com as atividades. Esse é um importante mecanismo de empoderamento, segundo Fung (2003), pois estabelece uma influência direta na definição da agenda escolar. Contudo, o papel do ativismo comunitário foi determinante para o estabelecimento e aprimoramento destas reformas. $\mathrm{O}$ autor ressalta que diversas entidades comunitárias protagonizaram uma onda reformista contra a 
centralização do controle das escolas pelo governo municipal. Em 1988, este movimento culminou na aprovação na lei de reformas das escolas de Chicago, na assembleia estadual do estado de Illinois, realizada em Springfield, estabelecendo os LSC's.

Em um segundo momento, a atuação comunitária foi determinante para o aprimoramento da qualidade das decisões deliberadas nos conselhos. Organizações não governamentais atuavam provendo treinamentos para os conselheiros para o melhor desempenho das suas funções. Este movimento surtiu efeitos tanto para contrabalancear os efeitos do despreparo dos membros do conselho nas atividades da escola, como também ressoou com a percepção do governo municipal da ineficácia da tomada de decisão coletiva nas unidades. Desta forma, em 1995, tornou-se obrigatória a capacitação dos conselheiros em aspectos da governança escolar, tais como: responsabilidades de cada conselheiro, orçamento, contratos, trabalho em equipe, elaboração do plano de ação e seleção de diretores.

Nota-se então que a participação comunitária institucionalizada no conselho configura-se não somente como uma adjacência, mas uma clivagem diante da atuação consolidada da sociedade civil nas reformas educacionais de Chicago. Este movimento permite diagnosticar que o estoque de capital social no município foi determinante para implementar a descentralização da gestão escolar e assegurar que este novo arranjo apresentasse resultados melhores que anteriormente, com a gestão centralizada. Reflexo imediato disso nos resultados é que, embora houvesse conflitos no processo de tomada de decisão, impedindo uma deliberação, estes eram casos isolados. Na maior parte dos conselhos, chegava-se a um consenso, a despeito dos conflitos. As partes consideravam melhor abrir mão de determinados pontos de vista em prol do coletivo, do que não tomarem uma decisão, e perderem a autogovernança, com o governo municipal assumindo a gestão da escola.

\subsection{0 arranjo organizacional e institucional das Charter Schools}

O segundo caso a ser estudado tem enfoque sobre o modelo norte-americano de Charter Schools, a partir da análise feita por Bifulco e Ladd (2005). Estas são escolas públicas, na qual a gestão é realizada por uma organização não governamental, sendo que o financiamento é competido ao Estado, sem que este exerça, necessariamente, influência sobre os aspectos administrativos e pedagógicos da instituição. $O$ contrato celebrado entre estas duas partes prevê a oferta gratuita de vagas a todos os públicos, de modo que, havendo uma demanda maior do que a capacidade suportada pela escola, é realizado um sorteio para a destinação das vagas.

Segundo os autores, a primeira lei que estabeleceu as Charter Schools foi promulgada em 1991, no estado de Minnesota e desde então, quarenta estados já teriam adotado esta política. Este movimento demonstra a inclinação governamental para descentralizar as decisões educacionais, uma vez que, além de delegar a outro ente a gestão escolar, possibilita aos pais a escolha da escola em que matriculará o seu filho. A hipótese do autor é de que diversos fatores organizacionais das Charter Schools fazem com que os pais dos seus alunos sejam mais participativos em comparação com as escolas tradicionais.

Os critérios utilizados para definir as características em comum das Charter Schools que incentivam este comportamento colaborativo são os seguintes: o menor tamanho da escola, se comparado às escolas tradicionais, a autonomia da escola perante aos órgãos governamentais, a possibilidade de escolher a escola mais adequada e, consequentemente, a competição gerada e seus possíveis desdobramentos. Deste modo, entende-se que todas estas decisões partem de uma posição governamental que orienta-se no sentido de estimular a participação e autonomia da sociedade como um tudo, uma vez que envolve os profissionais, os pais e a comunidade, por meio da sociedade civil organizada. Segundo Smith et al (2011), em 15 estados, a participação parental aparece como um objetivo, na lei que estabelece as Charter Schools, o que reforça esta tese. 
O arranjo em questão provê aos burocratas autonomia na execução dos seus serviços, na medida em que possuem baixa dependência de controles externos. No entanto, a delegação aos pais da escolha da instituição em que matricularão seus filhos cria um comportamento de competição entre as escolas. Desta forma, os profissionais das Charter Schools utilizem sua discricionariedade para prover mecanismos que gerem benefícios aos pais que apresentarem inclinação para a participação e coprodução. Dentre os resultados reportados no artigo, os esforços de estreitamento por meio da comunicação entre os pais e os professores, principalmente nos aspectos voltados à complementação do conteúdo ministrado na escola, além de serviços para assegurar a presença dos pais nas atividades da escola, foram estatisticamente significativos. Esses esforços demonstram que os profissionais prezam pela coprodução como um ativo que auxilia no seu trabalho, e mobilizam-se para institucionalizar práticas que favoreçam esse tipo de comportamento por parte dos pais.

A mesma lógica opera sobre a ação parental, uma vez que a discricionariedade dos profissionais, advinda da maior independência externa, estimula os pais a participarem da vida escolar, haja vista que poderão exercer maior influência nos resultados gerados. Aliado a isso, como lhes é permitido o direito de escola, sua tomada de decisão levará em conta a sua afinidade com as políticas pedagógicas da escola em questão, o que, em nível agregado, diminui os custos de participação, tendo em vista a relativa homogeneidade de ideias que os pais compartilham. Uma vez institucionalizada a participação dos pais como uma prática habitual, será incorporada na decisão de futuros pais, retroalimentando o ciclo, haja vista que selecionará os pais que já se predispõe a participar das atividades da escola. Este quadro pode alterar substancialmente quando o critério de seleção passa a ser o sorteio de vagas, uma vez pode tornar mais heterogêneo o grupo de pais, e assim, aumentar os custos de ação coletiva da participação. Embora os resultados de Bifulco e Ladd (2005) sejam categóricos em afirmar que o efeito marginal das Charter Schools é positivo sobre a participação dos pais, concluem que pode haver um viés de seleção, reunindo os pais com tendências a participação nestas escolas, o que resultaria em uma diminuição da participação no restante das escolas.

No concernente ao aspecto comunitário, os autores ressaltam que esse fenômeno pode interferir nos resultados da distribuição da participação, no sentido de que as Charter Schools em dois sentidos: primeiramente, estas iniciativas iriam se estabelecer onde há uma tradição prévia à participação, e em um segundo momento, após estabelecidas, atrair os pais afins à esse tipo de comportamento cooperativo. Este primeiro movimento consegue ser captado pelos autores, na medida em que escolas tradicionais em locais onde existe uma Charter School tem menos problemas com a participação dos pais, em comparação às demais. Sendo assim, é possível entender que o capital social da vizinhança exerce efeito no grau de participação dos pais, mesmo controlando os aspectos organizacionais e a heterogeneidade da distribuição nos dois modelos de instituição.

\subsection{Combinação dos dois arranjos: potencialidades e desafios}

Diante do arcabouço teórico e das análises de casos concretos, é possível conceber que a combinação de arranjos que favoreçam a autonomia deliberativa e a coprodução de serviços públicos podem funcionar como complementares, potencializando seus impactos na sociedade. A presente seção objetiva ressaltar quais são os benefícios que podem ser gerados, e, posteriormente, as barreiras que devem ser transpostas para que este resultado seja concretizado.

Segundo Fung e Writght (2003b), uma das grandes possibilidades da implementação da EPG é delegar autonomia à governança local e, ao mesmo tempo, construir estruturas accountability quanto ao governo central. Nesta relação, o governo, ao descentralizar a tomada de decisão para o conselho local, estabelece contrapartidas relacionadas ao monitoramento de desempenho, ao passo que capacita os conselheiros para o exercício destas funções. 
Sob este prisma, Hupe e Hill (2007) ressaltam que os burocratas no nível de rua estão imersos em uma rede com diversos atores, de hierarquias superiores, inferiores e pares, na qual a relação destes profissionais exigem accountabilities. Os autores ressaltam que estas múltiplas demandas podem gerar ações contraditórias, e que o arranjo institucional pode auxiliar em resultados mais estruturados. Desta forma, os preceitos da EPG constituem um arranjo sólido para direcionar as ações dos profissionais da linha de frente. Como resultados da descentralização, serão conferidos a estes maior discricionariedade, diluição de suas responsabilidades - com o advento dos inputs dos coprodutores - e fortalecimento das suas relações com a comunidade, gerando um laço mutualístico de accountability.

Além disso, os arranjos que englobam as teorias aqui defendidas têm grandes possibilidades de estimular o aprendizado democrático, descrito por Pateman (1992), na medida em que amplia as oportunidades de participação em nível local a públicos sem repertório de participação, o que, sucessivamente, tende a aprimorar as aptidões relacionadas ao exercício democrático participativo. A despeito disso, a consolidação das arenas de deliberação apresenta-se como potenciais atividades que fortaleçam os laços comunitários, gerando capital social, como ressaltado por Fearon (1997). Estes resultados foram observados por Heller (2001), com impactos como maior associativismo e criação de novas arenas de deliberação.

Por outro lado, embora a literatura aponte benefícios de relevo que respaldem tais implementações, ainda há muitos desafios há serem transpostos e discutidos. Neste seguimento Ostrom e Tiebout (1961) ponderam que a descentralização da tomada de decisões, por meio de um arranjo policêntrico, para uma microagregação tende a envolver as principais partes interessadas. Contudo, os autores ressaltam que esta deliberação tende a negligenciar externalidades negativas aos autores representados nesta instância, e, caberia ao governo central equalizar os efeitos, de modo que a decisão de um núcleo não prejudique seus pares.

A literatura tem tratado sobre as armadilhas da democracia participativa, preconizando que as relações entre governo e sociedade ocorrem em ambientes de assimetria informacional, o que produz resultados subótimos no que diz respeito a sensibilidade do governo para com as preferências da população, e na sua posterior execução (PLATTEAU, 2008). Dentro desse bojo, destaca-se o conceito de imperfeições comunitárias endógenas, como uma correspondência às imperfeições de mercado aplicadas nos contextos de governança comunitária reproduzindo desigualdades na distribuição dos recursos (PLATTEAU; ABRAHAM, 2004).

Nesse sentido, Cleaver (2005) discute sobre a desigualdade da distribuição do capital social e suas implicações na participação de diferentes públicos nas instituições participativas. O principal impacto desta heterogeneidade recai sobre a população mais pobre, que traduz-se nas baixas expectativas para comportamentos de cooperação e reciprocidade, fragilidade nas relações sociais e consequente dificuldade de mobilização e baixa capacidade de exercer representação efetiva em instituições participativas acessíveis a estes. Certamente, este mesmo fenômeno tende a prevalecer no caso de instâncias deliberativas, retroalimentando as desigualdades, uma vez locais com maior capital social tenderão a gerar soluções mais efetivas para os problemas, potencializadas pela coprodução que também está atrelada a este tipo de recursos.

Estas assimetrias sociais também potencializar problemas de ação coletiva cristalizando relações de poder. Um dos fenômenos apontados pela literatura que constituem uma das fragilidades do modelo à EPG são os riscos de captura das instituições políticas por grupos autointeressados dominando a agenda e o processo de tomada de decisão para que lhe gerem maior retorno (FUNG; WRIGHT, 2003a). A trajetória de tomada de decisões top-down em longas cadeias de comando faz com que determinados grupos com participação política prévia constituam um arcabouço de informações e conhecimentos locais que Ihes assegurem este domínio nas instâncias deliberativas (FUNG; WRIGHT, 2003b). Furh (2011) ressalta que é comum que elites locais se beneficiem de políticas de descentralização, em locais onde há uma baixa cultura de accountability 
e participação popular.

Na mesma redoma, surge a discussão sobre free-rider, como uma quebra da ação coletiva, na qual dentro de um grupo, um indivíduo ou um sub-grupo não arca com os custos, no entanto recebe os benefícios coletivos à custa dos demais (OLSON, 1965). Isso torna-se possível, uma vez que a coprodução da educação pelos pais de alunos pode resultar em ações que retornem tanto benefícios de cunho individual (e.g. auxiliar no dever de casa) como coletivo (e.g. participação em conselhos, organização de eventos, trabalho voluntário para a escola), como ressalta Bifulco e Ladd (2005).

E por último, reconhece-se o desafio de reproduzir em escala estas iniciativas, e de modo que esta descentralização consiga afetar a agenda nacional. Pogresbinchi (2013) ressalta que para transpor essa barreira, é necessário que uma política leve em consideração viabilidade, considerando as relações entre Estado e sociedade civil, um volume de potenciais participantes em cada instância que consiga ser representativo e exequível e um design institucional que consiga conectar o nível local ao nacional. Além disso, é preciso considerar a efetividade, dimensionando a capacidade de estabelecer consensos e de impactar os tomadores de decisão.

\section{Considerações Finais}

O presente artigo pautou-se por analisar questões relativas à sinergia Estado-sociedade, e potenciais mecanismos para aprimorar a sensibilidade de demandas e preferências entre os dois entes. Embasou-se em dois conceitos fundamentais que, apesar de abordarem esta temática, de forma análoga, derivam de áreas distintas da ciência. São estes: empowered participatory governance, sendo um arranjo específico ressaltado pelos teóricos da democracia deliberativa, e a co-produção, como um desdobramento da análise da provisão de políticas públicas dentro do estudo da economia do setor público.

Em suma, o primeiro conceito parte da descentralização de poderes, delegando o processo de tomada de decisão à instâncias locais, na medida em que o segundo parte da interação entre os atores da ponta na provisão de políticas públicas: os burocratas do nível de rua e os cidadãos beneficiários. Dentre as principais convergências entre os conceitos, o elo teórico que estabeleceu a associação entre estes foi o capital social, tendo em vista as implicações que as redes de cooperação e solidariedade formadas por indivíduos de uma mesma comunidade exercem sobre ambos.

A partir deste arcabouço teórico, utilizaram-se dois estudos de caso da literatura para analisar a conexão dos conceitos na prática. $O$ caso da rede escolar de Chicago iniciou-se com uma reforma que descentralizou a gestão de cada escola para seu respectivo conselho, e a partir da análise, percebeu-se que esta política surtiu efeitos em estimular a interação entre pais, professores e diretores, uma vez que estes deveriam ocupar as cadeiras do conselho. Embora não seja possível relatar resultados advindos da intensificação de relação entre estes atores, a efetividade da política de descentralização permite concluir o êxito na coprodução política, através do dispêndio de recursos nas atividades do conselho. O segundo caso analisou um modelo norte-americano de escolas autônomas denominado Charter Schools, que surge com o objetivo de permitir e intensificar a participação parental na educação. Considera-se que o modelo possui características organizacionais que favorecem a coprodução, no entanto, não é possível constatar resultados que transcendam o ambiente escolar e se espraiem para a comunidade ou para o ambiente político.

A combinação destes dois arranjos pode contribuir largamente para o desenvolvimento da democracia deliberativa em nível local, bem como para intensificar as redes de cooperação comunitárias, e criar relações de responsividade entre estado e sociedade. Todavia, há grandes dificuldades de reproduzi-lo em escala, 
uma vez que é necessário considerar as heterogeneidades sociais para que não sejam produzidos resultados não esperados, tais como a captura de poder por elites locais e dilemas de ação coletiva que reforcem distribuições desiguais de recursos.

Por fim, como um diálogo inicial entre os dois conceitos, o trabalho possui limitações metodológicas na análise que se propõe. Sugere-se para pesquisas futuras analisar empiricamente este fenômeno coletando dados de fontes primárias. Outrossim, pesquisar o impacto da implementação de instâncias deliberativas sobre o estabelecimento de agendas macropolíticas, tal como a potencial influência no fortalecimento de uma cultura cívica e participativa. Estas e outras eventuais lacunas do presente estudo que, uma vez preenchidas em análises futuras, podem corroborar com o amadurecimento do tema, seja como área de pesquisa ou um potencial arranjo para implementação piloto de projetos reais.

\section{REFERÊNCIAS}

ABERS, Rebecca Neaera. Reflections on what makes empowered participatory governance happen. Deepening democracy: Institutional innovations in empowered participatory governance, p. 200-207, 2003.

ABERS, Rebecca Neaera; KECK, Margaret E. Mobilizing the state: The erratic partner in Brazil's participatory water policy. Politics \& Society, v. 37, n. 2, p. 289-314, 2009.

AVRITZER, Leonardo. O orçamento participativo e a teoria democrática: um balanço crítico. A inovação democrática no Brasil. São Paulo: Cortez, p. 13-60, 2003.

BIFULCO, Robert; LADD, Helen F. Institutional change and coproduction of public services: The effect of charter schools on parental involvement. Journal of Public Administration Research and Theory, v. 16, n. 4, p. 553-576, 2005.

BOBBIO, Luigi. Building social capital through democratic deliberation: the rise of deliberative arenas. Social Epistemology, v. 17, n. 4, p. 343-357, 2003.

BOBBIO, Norberto. The future of democracy. Telos, v. 1984, n. 61, p. 3-16, 1984.

BOVAIRD, Tony. Beyond engagement and participation: User and community coproduction of public services. Public administration review, v. 67, n. 5, p. 846-860, 2007.

CLEAVER, Frances. The inequality of social capital and the reproduction of chronic poverty. World development, v. 33, n. 6, p. 893-906, 2005.

DAVIS, Gina; OSTROM, Elinor. A public economy approach to education: Choice and co-production. International Political Science Review, v. 12, n. 4, p. 313-335, 1991.

EVANS, Peter. Government action, social capital and development: reviewing the evidence on synergy. World development, v. 24, n. 6, p. 1119-1132, 1996.

Constructing the 21st-century developmental state-potentialities and pitfalls. New Agenda: South African Journal of Social and Economic Policy, v. 36, p. 6-13, 2009.

FEARON, James D. Deliberation as Discussion In: Elster J, editor. Deliberative Democracy. 1998.

FUHR, Harald. The seven traps of decentralization policy. Bisnis \& Birokrasi Journal, v. 18, n. 2, 2012.

FUNG, Archon; WRIGHT, Erik Olin. Deepening democracy: innovations in empowered participatory governance. Politics \& Society, v. 29, n. 1, p. 5-41, 2001. 
FUNG, Archon. Countervailing Power in Empowered Participatory Governance Archon Fung and Erik Olin Wright. Deepening democracy: Institutional innovations in empowered participatory governance, $v$. 4, p. 259,2003

HIRSCHMAN, Albert O. Against parsimony: Three easy ways of complicating some categories of economic discourse. Bulletin of the American Academy of Arts and Sciences, v. 37, n. 8, p. 11-28, 1984.

HELLER, Patrick. Moving the state: the politics of democratic decentralization in Kerala, South Africa, and Porto Alegre. Politics \& Society, v. 29, n. 1, p. 131-163, 2001.

HELLER, Patrick; ISAAC, Thomas. O perfil político e institucional da democracia participativa: lições de Kerala, Índia. Democratizar a democracia. Os caminhos da democracia participativa, p. 497-535, 2003. HUPE, Peter; HILL, Michael. Street-Level bureaucracy and public accountability. Public administration, v. 85, n. 2, p. 279-299, 2007.

LOTTA, Gabriela Spanghero; PIRES, Roberto Rocha Coelho; OLIVEIRA, Vanessa Elias. Burocratas de médio escalão: novos olhares sobre velhos atores da produção de políticas públicas. 2014.

LIPSKY, Michael. Street-level bureaucracy. Dilemmas of the Individual in Public Services, 1980.

MARCH, James G.; OLSEN, Johan P. Rediscovering institutions. Simon and Schuster, 2010.

OLSON, Mancur. Logic of collective action: Public goods and the theory of groups (Harvard economic studies. v. 124). Harvard University Press, 1965.

OSTROM, Elinor. Crossing the great divide: coproduction, synergy, and development. World development, v. 24, n. 6, p. 1073-1087, 1996.

OSTROM, Vincent; TIEBOUT, Charles M.; WARREN, Robert. The organization of government in metropolitan areas: a theoretical inquiry. American political science review, v. 55, n. 4, p. 831-842, 1961.

PARKS, Roger B. et al. Consumers as coproducers of public services: Some economic and institutional considerations. Policy Studies Journal, v. 9, n. 7, p. 1001-1011, 1981.

PATEMAN, Carole. Participação e teoria democrática, trad. Luiz Paulo Rouanet. Rio, 1992.

PATEMAN, Carole. Participatory democracy revisited. Perspectives on politics, v. 10, n. 1, p. 7-19, 2012.

PESTOFF, Victor. Towards a paradigm of democratic participation: citizen participation and co-production of personal social services in Sweden. Annals of Public and Cooperative economics, v. 80, n. 2, p. 197-224, 2009.

PIZZORNO, Alessandro; CASTELLS, Manuel; KAPLAN, Marcos. Participación y cambio social en la problemática contemporánea. 1975.

PLATTEAU, Jean Philippe. Pitfalls of participatory Development. United Nations. http://www. fundp. ac. be/pdf/publications/61702. pdf, 2008.

PLATTEAU, Jean-Philippe; ABRAHAM, Anita. Participatory development in the presence of endogenous community imperfections. Journal of Development Studies, v. 39, n. 2, p. 104-136, 2002.

POGREBINSCHI, Thamy. The squared circle of participatory democracy: Scaling up deliberation to the national level. Critical Policy Studies, v. 7, n. 3, p. 219-241, 2013.

PRATES, Antônio Augusto P. et al. Capital social e redes sociais: conceitos redundantes ou complementares. Desigualdades sociais, redes de sociabilidade e participação política. Belo Horizonte: UFMG, 2007. 
PUTNAM, Robert D. Comunidade e democracia: a experiência da Itália moderna. editora FGV, 2002.

SMITH, Joanna et al. Parent involvement in urban charter schools: New strategies for increasing participation. School Community Journal, v. 21, n. 1, p. 71-94, 2011.

TAYLOR, lan; KELLY, Josie. Professionals, discretion and public sector reform in the UK: re-visiting Lipsky. International Journal of Public Sector Management, v. 19, n. 7, p. 629-642, 2006.

WARREN, Mark E. What can democratic participation mean today?. Political theory, v. 30, n. 5, p. 677-701, 2002. 